\title{
Shukiurlu Yu.,
}

Candidate of Physical and Mathematical Sciences

Bekirov G.,

Candidate of Biological Sciences

Bakirova Ye.

Shaikin Regional Scientific Center of the National Academy of Sciences of Azerbaijan (NERC)

\section{ASSESSMENT OF ECONOMIC EFFICIENCY OF REGIONIZED VARIETIES AND HYBRIDS OF SILKWORM}

The purpose. Calculation of economic efficiency of breeds and hybrids of silkworm. Methods. Questions of estimation of economic efficiency of the gained and zoned breeds and hybrids of silkworm GS-143xŞzem-4, ŞZEM4xGS-143, ŞZEM-4 and GS-143 are surveyed. Results. Economic efficiency of the tested breeds and hybrids in comparison with control hybrids Sheki1xSheki-2. Economic efficiency is calculated of the gained and zoned breeds and hybrids GS-143xŞzem-4, ȘZEM-4xGS-143, ŞZEM-4 and GS-143. Mass of production of crude cocoon, quotient of exit of dry cocoon and crude cocoon and mass of raw silk is determined. Conclusions. It is proved that hybrids and cultivars of silkworm GS-143xŞzem-4, ŞZEM-4xGS-143, ŞZEM-4 and GS-143 have displayed higher economic efficiency, than that ones from control hybrids Sheki-1xSheki-2.

Key words: breed, hybrid, cocoon, economic efficiency, selection.

Objective evaluation of rocks and hybrids of siltsmith is of great importance for the development of silkworm. The species and hybrids under study are evaluated for reference breeds and hybrids. This comparison, taking into account some biological, technological and productive indicators, is carried out separately for each indicator, which confirms the objectivity of the final evaluation of breeds and hybrids. Methodology and results of research. Determination of the economic efficiency of breeds and hybrids is the main objective of the study, obtained as a result of breeding works in silkworm. This method makes it possible to determine the profitability of numerous breeds and hybrids to a sufficient degree and to integrate the assessment of breeds and hybrids based on comparison of averages. It is known that economic efficiency (profit and loss) originates in the production of any product of material value. From each breed and hybrids get raw cocoon, dry cocoon and raw silk. Separately, each type of product can revive economic efficiency. BG Abbasov notes that the overall economic efficiency of each 
breed and hybrid compared with the control ones is the sum of the three productive indicators, or more precisely the additional income [1]. IA Strunnikov, during the incubation of greens of hybrids and pure breeds at a temperature of $33^{\circ} \mathrm{C}$ and $32 \%$ moisture content, determined the heterosensitivity [2]. Prof. K. B. Svechin proposes to define heterozosis by the formula:

$$
\mathrm{Hi}=\mathrm{En} / \mathrm{Ep} \cdot \mathrm{m} \times 100 \text {, }
$$

where $\mathrm{Hi}$ - heterosis index; $\mathrm{En}$ - any sign received in the first generation; Ep.m - any sign of the father [3]. AM Safonova in his work [4] indicates that, with respect to control samples, the highest index of cocoon mass is 18 $20 \%$, and the silk content of the raw cocoon is $25.6 \%$. The feeding period for hybrids, obtained as a result of studies conducted by GA Azimov, GM Bekirov, for 2 - 3 days less than used today. Grain survival - by $5-7 \%$, trackback capacity - by 15 - 20, silk - by 5 - 8 , absolute silk output - by 10 12 , ability to unwind - by $10-15$, thread length - by $20-25$, output of $1 \mathrm{~g}$ of products - by 30 - $35 \%$ exceeds these indicators from parents [5]. We determined the economic efficiency of the obtained and zoned 2 breeds and 2 hybrids by the Shakespeare Regional Scientific Center Selection Center for control specimens. For this purpose, the average indices of rocks and hybrids GS-143 × ŞZEM-4, ŞZEM-4 × GS-143, ŞZEM-4, GS-143 relative to the control samples of Sheki-1 $\times$ Sheki-2 were taken. At current prices, the cost of $1 \mathrm{~kg}$ of raw cocoon was estimated at 1.4 cents; $1 \mathrm{~kg}$ of dry cocoons 4 cents. Species and hybrids of the silkworm differ in size, weight and other features. The production of one box of Sheki- $1 \times$ Sheki- 2 control samples is $90.84 \mathrm{~kg}$. A high rate was obtained for the obtained and zoned breeds and hybrids of the silkworm GS-143 $\times$ ŞZEM-4, ŞZEM $-4 \times$ GS-143, ŞZEM -4, GS143 relative to the control samples: in the GS-143 $\times$ hybrids ŞZEM -4 - 92, 69 $\mathrm{kg}$, ŞZEM -4 × GS-143-91.36 kg, in the rocks of ŞZEM -4 - $92.25 \mathrm{~kg}$, GS-143 - $91.04 \mathrm{~kg}$ of raw coconut. For the determination of economic efficiency, the value of specific products and production costs for the production of these products from one tray of new and control samples are calculated. Under normal conditions, the production costs for incubating one box of gravel and the care of the same silkworm tracks do not depend on the rocks and hybrids of the silkworm - they are the same. The economic benefit, that is, the profit derived from one box of the new breed and the hybrids of the silkworm, in comparison with the control samples, is calculated as follows: the price of 1 $\mathrm{kg}$ of raw cocoon is estimated by the raw cocon production values obtained from one box of new grains. The economic benefit derived from one box of new and raioned rocks and hybrids in comparison with the control samples of 
rye silkworm at the expense of raw cocoon production was higher by 2.6 cents of the USA in GS-143 $\times$ ŞZEM -4 , at 0.7 cents of the USA in There are ŞZEM $-4 \times$ GS-143, for 2 cents in the US- 4 and 0,3 cents in the GS-143. The output of a dry cocoon is a profitable production indicator; it determines the yield of a dry cocoon. This indicator varies depending on the biological characteristics, the ratio of silkworm and the average mass of the raw cocoon. The difference in the mass of raw and dry cocoons of the studied breeds and hybrids is $36.93 \mathrm{~kg}-\mathrm{GS}-143 \times$ ŞZEM -4, $36.99 \mathrm{~kg}-$ ŞZEM -4 × GS-143, $37.05 \mathrm{~kg}$ - ŞZEM -4, 37, 16 - GS-143, and in control samples $36.48 \mathrm{~kg}$. Consequently, the obtained and raisin breeds and hybrids of the silkworm produced a higher result than the control samples. Based on this, one can conclude that the economic benefit, that is, the net profit exceeds 1.7 cents in GS-143 × ŞZEM -4; 1.9 cents in the United States - in the ŞZEM -4 $\times$ $\times$ GS-143; 2.1 cents of the United States - with the ŞZEM -4, and GS-143 2.5 cents of the US control samples. To obtain $1 \mathrm{~kg}$ of silk from new and districted breeds and hybrids, $2.70 \mathrm{~kg}$ is required from GS-143 $\times$ ŞZEM -4; $2.77 \mathrm{~kg}$ - with ŞZEM $-4 \times$ GS-143; $2.80 \mathrm{~kg}$ - ŞZEM -4, $2.80 \mathrm{~kg}$ from GS-143, while from control samples $-2.90 \mathrm{~kg}$. The smaller the dry coconal is required to get $1 \mathrm{~kg}$ of raw silk, the lower the material value, and this is the main indicator that affects the performance of silk. This indicator is higher in the received and zoned rocks and hybrids with respect to control samples: they receive $12.58 \mathrm{~kg}$ of raw silk from $20 \mathrm{~g}$ of raw silk, in GS-143 $\times$ ŞZEM -4 $14.20 \mathrm{~kg}$; in ŞZEM -4 × GS-143 - 13.35; in ŞZEM -4 - 13.23; GS-143 - 13.27 $\mathrm{kg}$.

Receiving a large number of products - the main indicator of production. It is clear from the norms that for the production of $1 \mathrm{~kg}$ of raw silk, in addition to the cost of obtaining a dry cocoon, all other production costs are the same. In view of these indicators, profit and economic efficiency can be determined by obtaining from a single box of grains new breeds and hybrids from the dry cocoon of raw silk relative to the corresponding control samples. The economic benefits and profits of one box of gravel of new breeds and hybrids is: 11 US cents - in GS-143 × ŞZEM -4; 7.2 cents in the US- ŞZEM -4 × GS$143 ; 5.3$ cents of the USA - at the Jesem-4; 5.3 US cents - GS - 143 for control samples.

\section{Conclusions}

The economic benefit obtained from the raw cocoons from one box of grenadas in the silkworm lines grown in the "Selection of siliceous silage" section of the SCRC exceeds 2.6 cents in GS-143 $\times$ ŞZEM $-4 ; 0.7$ cents of the United States - with the Jesem-4 $\times$ GS-143; 2 US dollars - at the ŞZEM 4 ; 0.3 cent US - GS-143 for reference samples of the hybrid (Sheki-1 $\times$ 
Sheki-2). Net profit due to the output of dry cocoon from raw cocoons is high: at 1.7 centners, and in the USA - GS-143 $\times$ ŞZEM -4; for 1,9 centners in the USA - for the Jesem-4 × GS-143; for 2,1 cents of the USA - for the ŞZEM -4, and for the GS-143 variety - by 2,5 cents of the USA higher than the control samples.

\section{Bibliography}

1. Abbasov B.H. You will be asked if you want to learn or practice. Gəncə: Elkin MMC 2009. - $277 \mathrm{~s}$.

2. Strunnikov B.A. Comparative viability of females and males in the rocks labeled on the floor, at the stage of the egg/B.A. Strunnikov - Tashkent, 1976. - Vip. 10. - P. 131 - 134.

3. Svechin K. B. Estimation of the heterosis effect in relative indicators/K.B. Candy//Livestock breeding. - 1967. - No. 1. - P. 61 - 62.

4. Safonova A. M. Scientific fundamentals of the development of silkworm/AM. Safonova - Tashkent, 1977. - 206 p.

5. Jzimova Q.A. Tut ipəkqurdunun genetik ehtiyatlarэnэn zənginləюdirilməsində klasik ьsullarən istifadəsi/Q.A. Żezimova, Q.M.

Bəkirov//Biomüxtalifliyin Genetik ehtiyatları. - I will be at the Elmi confessed material. - Baki, 2006. - P. 229-230.

6. Abdullaev I.K. Polyploidy in the selection of silk/l.K. Abdullaev//Reports of the Academy of Sciences of the Azov SSR. - 1963. - Bibliography T. 1. - S. $26-29$.

7. Ataurov B. L. Biological effect of temperatures and lifelong thermal decontamination/B.L. Astaurov//Infectious and Protozoal Diseases of Useful and Harmful Insects. - M .: Sel'khozgiz, 1956. - P. 63 - 93.

8. Badalov N.G. A new breed of tall sheepskin with high payment of food and labeled by sex at the egg stage/N.G. Badalov//Silk. - 1981. - No. 5. - P. 9-10.

9. Bogautdinov N.G. On the temperature of the body of caterpillars of mare silkworm/N.G. Bogautdinov//Silk. - 1960. - № 1. - P. 47 - 49.

10. Huseynov R. A. Silkworm in Japan/R.A. Huseynov - M., 1979. - P. 86.

11. Ikramov Z.I. At Fergana breeding silk station/Z.I. Ikramov//Silk. - 1978. - No. 6. - P. 9. 